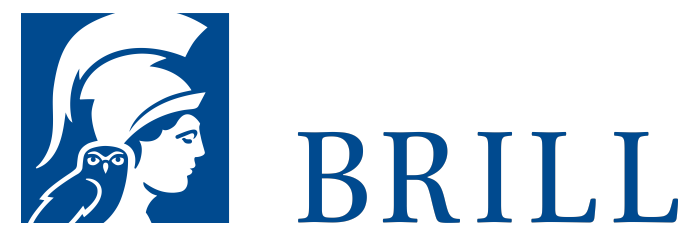

\title{
Quantentheorie der Information
}

Zur Naturphilosophie der Theorie der Ur-Alternativen und einer abstrakten Theorie der Information

Author: Holger Lyre

Die Quanteninformationstheorie bildet eines der faszinierendsten Arbeitsgebiete der modernen Physik. Ihre rasche Entwicklung ist von den sich eröffnenden technischen Möglichkeiten getrieben. Carl Friedrich von Weizsäcker hat jedoch bereits in den 6oer Jahren einen tiefliegenden Zusammenhang zwischen einer radikalen Quantentheorie binärer Alternativen, also Quantenbits, und der Struktur der Raum-Zeit vermutet und in Form einer "Quantentheorie der UrAlternativen" zu entwickeln versucht. In der vorliegenden Arbeit wird den diesbezüglichen philosophisch-begrifflichen wie auch physikalisch-mathematischen Zusammenhängen von Informations- und Quantentheorie nachgespürt. Ausgehend von Weizsäckers "Ur-Theorie" wird eine abstrakte Theorie der Information in transzendentalphilosophischer Perspektiye entworfen und es werden die begrifflichen Implikationen einer konsequenten Quantentheorie der Information umfassend diskutiert. Das Buch präsentiert eine Fülle von Material aus den Bereichen Informations- und Komplexitätstheorie, Quantentheorie und Raum-Zeit-Physik sowie der Philosophie der Physik. Seine philosophische Kernthese ist, dass der Begriff der Information im Wesentlichen aus den zwei apriorischen Vorannahmen der Unterscheidbarkeit und Zeitlichkeit begründbar ist.

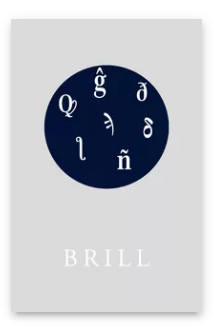

Pages: 282 Seiten Language: German Subjects: 19 th \& 2oth Century Philosophy, Philosophy Publisher: Brill | mentis

E-Book (PDF) Released online: 3o Sep 2004 ISBN: 978-395743-907-9

Paperback Publication date: 3o Sep 2004 ISBN: 978-3$89785^{-237-2}$ 
For more information see brill.com

Order information: Order online at brill.com +44330 333 0049 | customerservices@brill.com Submission information: brill.com/authors

Titles published by Brill | Fink, Brill | mentis or Brill | Schöningh: +49(o)715413279216| brill@brocom.de 